\title{
Assessment and management of asthma in an accident and emergency department
}

\author{
S REED, S DigGle, MJ CUShley, RA SLEET, AE TATTERSFIELD
}

From the Department of Respiratory Medicine and the Accident and Emergency Department, Southampton General Hospital, Southampton

ABSTRACT Patients with asthma presenting to the accident and emergency department at Southampton General Hospital during 12 months were reviewed retrospectively to determine how many patients attended, when and how patients were assessed and treated, and what factors appeared to influence whether a patient was admitted to a medical ward or not. Thirty five visits were made by patients requesting a repeat prescription for a metered dose inhaler. A further 193 visits were made by 152 patients ( 93 male, 59 female); only data on the first visit of any individual were analysed in this study. Patients were more likely to visit in the autumn, at the weekend, and in the evenings. Observations and measurements used to assess the severity of asthma were recorded with variable frequency-heart rate in $84 \%$ of examinations, pulsus paradoxus in $13 \%$, and peak flow rate in $11 \%$. Blood pressure was five times more likely to be recorded than peak flow rate. The drugs used to treat asthma were, in order of frequency, a $\beta$ agonist (120 patients), intravenous aminophylline (39), and intravenous corticosteroids (30). Sixty (39\%) of the patients were admitted to a medical ward. Admission was more likely to occur when patients arrived during the week than at the weekend, when they had cyanosis or pulsus paradoxus, and after receiving parenteral treatment. There was no difference in mean heart rate between patients admitted to the ward and those discharged home. Although there was no specific evidence of inappropriate admission to or discharge from hospital in this retrospective study, the failure to record more objective measurements of the severity of asthma and, in particular, the extent of the airflow obstruction, is cause for concern.

In the event of an exacerbation of asthma, patients have several options; they may treat themselves, visit their general practitioner, attend a hospital casualty department, or be admitted to a medical ward directly. Despite changes in medical practice, and many advances in the treatment of asthma over the past 30 years, there has been no reduction in the mortality rate. Apart from the transient increase in the 1960 s, the number of deaths each year in Britain has remained about $1500 .^{1}$

Several studies have tried to determine why patients die from asthma. Some have looked at the assessment and management of exacerbations of asthma in general practice ${ }^{2}$ and hospital, ${ }^{3-6}$ while others have looked at individual deaths from asthma in an attempt to identify factors related to mortality. ${ }^{7-11}$

Address for reprint requests: Dr MJ Cushley, Department of Medicine I, General Hospital, Southampton SO9 4XY.

Accepted 1 July 1985
All have suggested that there are deficiencies in both assessment and treatment.

Studies on patients presenting to an accident and emergency department with asthma have been reported from the United States, ${ }^{12-14}$ where the management policy differs from that in the United Kingdom and patients may remain in the accident and emergency department for up to 24 hours. No such study has been reported from the United Kingdom. This prompted us to carry out a retrospective review of all patients presenting with asthma to the accident and emergency department at Southampton General Hospital during 12 months. In Southampton junior casualty officers, as in many other hospitals in the United Kingdom, are divided equally between those on surgical rotations and those in general practitioner vocational training schemes. They receive formal instruction on the management of common conditions such as asthma, and this is reinforced with a typed protocol displayed in the accident and emergency department describing the management of 

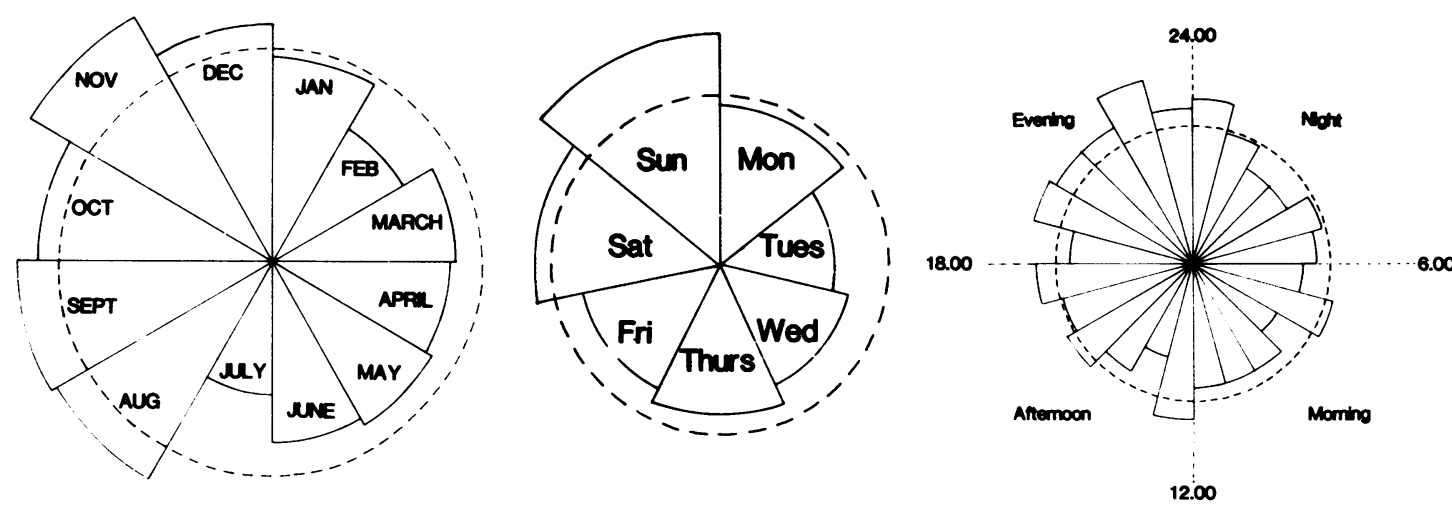

Fig 1 Number of attendances at the accident and emergency department according to (a) month, (b) day, (c) hour. The dotted line represents the expected number of attendances with asthma if there were no variation in admission rate during each period-that is, 12.7 admissions for each month, 21.7 for each day, and 6.1 for each hour.

acute exacerbations of asthma. This study was designed to determine (1) how many patients attended because of asthma and when they attended; (2) how patients were assessed and treated; and (3) what factors appeared to influence whether a patient was admitted to hospital or discharged.

\section{Methods}

When patients attend the accident and emergency department details of the presenting complaint are recorded in an admission book by the receptionist. This book was screened for the 12 months December 1981-November 1982, to identify patients presenting with any of the chest related symptomsasthma/asthmatic, chest problems, shortness of breath, chest infection, breathlessness, breathing problems, trouble or difficulty with breathing, bronchial problems, chesty, wheezing, respiratory problems, distress, allergy, resuscitation, pneumothorax. The accident and emergency records of those patients were then examined. Chest pain was not included as a pilot study of 30 patients showed that none was suffering from asthma.

A questionnaire was completed from the records of every patient who received the final diagnosis of asthma. The questionnaire covered four main areas: (1) general details-(a) age, sex, address, general practitioner; $(b)$ the patient's history, including previous asthma, duration of symptoms, precipitating factors, and route and time of admission.

(2) how the severity of the attack was assessed in the accident and emergency department - (a) observation (difficulty in speaking, dyspnoea, distress, use of accessory muscles, cyanosis). (b) measurements (heart rate, respiratory rate, pulsus paradoxus, peak expiratory flow rate $(\mathrm{PEF}), \mathrm{FEV}_{1}$. $(c)$ investigations (chest radiography, electrocardiography, arterial blood gas measurements).

(3) Treatment received: $(a)$ before arrival in the accident and emergency department; $(b)$ in the department.

(4) whether the patient was admitted to hospital or discharged.

This information was analysed on an ICL 2970 computer to obtain a one way frequency distribution for each variable and the relationship between selected variables.

A further questionnaire and explanatory letter were sent to all patients seen in the accident and emergency department during the last three months of the study. The purpose of this questionnaire was to find out, firstly, whether further treatment was needed after discharge from the accident and emergency department or hospital, and when the patient returned to normal activities or work; secondly, how often the patients had consulted his or her general practitioner in the past 12 months and had attended an accident and emergency department or outpatient clinic, or been admitted to hospital because of asthma in the past five years.

The results from patients discharged home from the accident and emergency department were compared with those from patients admitted to a medical ward by means of the $\chi^{2}$ test. The project was approved by the Southampton ethical committee. The consent of general practitioners was obtained before patients were approached at home.

\section{Results}

DETAILS OF PATIENTS

Of the total of 48805 patients attending the accident and emergency department (38 856 trauma and 9949 
Table 1 Percentage of the 152 patients for whom each variable was recorded

\begin{tabular}{|c|c|}
\hline & $\%$ recorded \\
\hline $\begin{array}{l}\text { Age } \\
\text { Sex } \\
\text { Date } \\
\text { Hour of admission } \\
\text { Route of admission } \\
\text { History } \\
\text { Known asthmatic } \\
\text { Duration of symptoms } \\
\text { Precipitating cause } \\
\text { Observations } \\
\text { Distress } \\
\text { Dyspnoea } \\
\text { Speech } \\
\text { Use of accessory muscles } \\
\text { Cyanosis } \\
\text { Tachypnoea } \\
\text { Chest auscultation } \\
\text { Measurement } \\
\text { Heart rate } \\
\text { Blood pressure } \\
\text { Pulsus paradoxus } \\
\text { Respiratory rate } \\
\text { Peak flow rate } \\
\text { Investigations } \\
\text { Chest radiograph taken } \\
\text { finding recorded } \\
\text { Arterial blood gases } \\
\text { Electrocardiogram } \\
\text { Treatment } \\
\text { Before admission } \\
\text { In accident and emergency department } \\
\text { Follow up } \\
\text { Admitted/discharged }\end{array}$ & $\begin{array}{l}98 \\
100 \\
100 \\
97 \\
25 \\
88 \\
70 \\
57 \\
26(13) \\
37(30) \\
13(7) \\
18(14) \\
43(9) \\
7 \\
96 \\
\\
84 \\
63 \\
13 \\
32 \\
11 \\
68 \\
56 \\
2 \\
1 \\
78 \\
93 \\
99\end{array}$ \\
\hline
\end{tabular}

*The percentages in parentheses indicate those with positive findings.

non-trauma) during the 12 months of the study, 428 attended as a result of chest symptoms, of whom 229 $(0.48 \%)$ received the final diagnosis of asthma. The

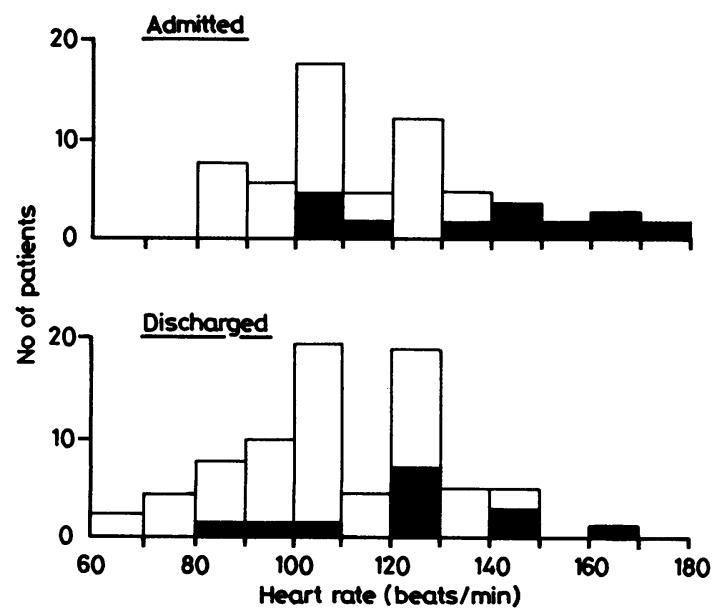

Fig 2 Heart rate (beats/min) for patients (a) admitted to the ward and $(b)$ discharged home from the accident and emergency department. Hatched areas represent recordings for patients less than 16 years of age. diagnosis in the remaining patients included croup, bronchitis, pneumonia, pneumothorax, and myocardial infarction. Thirty five visits were from patients only requesting a repeat prescription for a metered dose inhaler. One patient was dead on arrival. The remaining 193 attendances were made by 152 patients. Nineteen patients attended more then once, one on 13 occasions. The present analysis is restricted to the first attendance in 152 patients.

The 93 male and 59 female patients ranged in age from 2 to 79 years, with a mean of 27 years; $121(80 \%)$ were under the age of 40 . Ninety two patients $(61 \%)$ were discharged home from the accident and emergency department and $60(39 \%)$ were admitted to medical wards (two observations missing).

TIME OF ATTENDANCE (fig 1)

A significant seasonal variation was found, with the maximum number of attendances in November (22) and the minimum in July $(5)(p<0.01)$. More patients attended at the weekend, with $47 \%$ of patients presenting between midnight Friday and midnight Sunday, compared with the expected value of $29 \%$ if attendance had been uniform $(p<0.001)$. There was no increase in the number of patients admitted to the medical wards at the weekend, but twice as many patients were discharged home from the accident and emergency department as at other times. The greatest number of attendances was on Sunday (43) and the smallest on Tuesday (11). Dividing the 24 hour day into three eight hour periods showed that more patients arrived at $1600-2400 \mathrm{~h}(43 \%)$ than at $0000-0800 \mathrm{~h}(29 \%)$ or $0800-1600 \mathrm{~h}(28 \%)(\mathrm{p}<0.05)$.

\section{PAST HISTORY OF ASTHMA}

Ten patients had not been known to have asthma previously. Of the 106 patients in whom the duration of the attack has been recorded, 90 said they had had symptoms of worsening asthma for less than 24 hours and only five had had symptoms for more than seven days. A possible precipitating cause was recorded for over half $(57 \%)$ of the patients, the two most common being infection $(62 \%)$ and having run out of medication $(21 \%)$.

\section{ASSESSMENT OF SEVERITY \\ Recorded observations}

There were large differences in the percentage of patients for whom each variable had been recorded in the accident and emergency departments records (table 1). Distress, dyspnoea, cyanosis, inability to speak, and use of accessory muscles were not commented on for most patients. Chest auscultation was commented on most frequently $(96 \%)$, and the patient's ability to speak least often (13\%). The most frequent positive finding was dyspnoea $(30 \%)$. 


\section{Measurements}

Heart rate was documented in $84 \%$ of patients, pulsus paradoxus in $13 \%$, peak expiratory flow rate (PEF) in $11 \%$, and respiratory rate in $32 \%$, though a further $7 \%$ were said to be tachypnoeic. Heart rate (fig 2) ranged from 64 to 170 beats/min (mean 109) and was significantly higher in patients under 16 years of age (mean 125 beats $\mathrm{h} / \mathrm{min}$ ) than in those over 16 years (mean 104 beats/min; $p<0.01$ ). Pulsus paradoxus of $10 \mathrm{~mm} \mathrm{Hg}$ or greater was noted to be present in 15 and absent in five of the patients in whom it was recorded. The highest value was $60 \mathrm{~mm} \mathrm{Hg}$. Respiratory rate varied from 18 to 60 breaths/min (mean 31 ) and was significantly higher in patients under 16 years of age (mean 35 breaths/min) than in older patients (mean 29 breaths/min; $p<0.05$ ). PEF was measured in 17 patients -in 10 before treatment only, in three after treatment only, and in four both before and after treatment. The last four patients were all discharged. Five of the seven patients with a PEF below 200 1 min $^{-1}$ on arrival were admitted to a medical ward. No patient had a measurement of $\mathrm{FEV}_{1}$.

\section{Investigations}

Of the 103 chest radiographs obtained, 16 were reported as abnormal, although most of the abnormalities were coincidental. One patient had a pneumothorax which had not been detected clinically. Although it was stated that arterial blood gases were measured in three patients, no values were recorded. Two patients had an electrocardiogram.

\section{TREATMENT}

Before arrival in the accident and emergency department

Of the 119 patients in whom treatment before arrival in the accident and emergency department was noted, five had received no medication. The other patients were taking an average of two drugs, 104 were taking a $\beta$ agonist and 40 were taking corticosteroid treatment -22 by the inhaled route and 17 orally, of whom 12 were having regular oral corticosteroid treatment. Seven patients had received parenteral treatment: hydrocortisone (three patients), sal- butamol (one), and aminophylline (five - two of these patients having also had hydrocortisone). Usually the notes did not allow the treatment received for the present exacerbation to be clearly separated from previous maintenance treatment.

\section{In the accident and emergency department}

There was no record of treatment received in the accident and emergency department in 11 cases. No treatment was given to 10 patients - of whom nine were reassured and advised to continue with the medication they were already taking and one was admitted directly to the paediatric ward. The other 131 patients received an average of two drugs. One hundred and twenty received a $\beta$ agonist (89 via a nebuliser, 48 via a metered dose inhaler, and five orally); 20 patients received a $\beta$ agonist by two routes and one by three (inhaled, oral, and intravenous). Thirty patients were given intravenous corticosteroids, 39 intravenous aminophylline, and 24 patients both drugs. Twenty patients received antibiotics.

\section{FACTORS AFFECTING ADMISSION TO MEDICAL WARD}

There was no significant difference between patients admitted to a medical ward and those discharged home from the accident and emergency department with respect to age, sex, heart rate (mean $112 v 117$ beats/min respectively), and respiratory rate. Patients who came during the week were more often admitted than those attending at the weekend $(p<0.001)$, and those noted to be cyanosed ( $p<0.01$ ), those with pulsus paradoxus $(\mathrm{p}<0.01$ ), and those receiving parenteral treatment in the accident and emergency department $(p<0.001)$ were also more likely to be admitted. Patients with a PEF below $2001 \mathrm{~min}^{-1}$ on arrival were admitted more often, though this difference did not reach significance in the small group of 17 in which it was measured. Mean PEF was 1301 $\min ^{-1}$ in patients admitted to the ward, compared with $2401 \mathrm{~min}^{-1}$ in patients discharged home.

FOLLOW UP QUESTIONNAIRE

Sixty six patients attended the accident and emergency

Table 2 Comparison of recovery between the 18 patients discharged home from the accident and emergency department and the 18 discharged home having first been admitted to a medical ward

\begin{tabular}{|c|c|c|c|}
\hline & $\begin{array}{l}\% \text { of patients discharged } \\
\text { from } A \text { and } E\end{array}$ & $\begin{array}{l}\% \text { of patients discharged } \\
\text { from medical ward }\end{array}$ & p value \\
\hline $\begin{array}{l}\text { Return to normal activities within } 48 \text { hours } \\
\text { Needed additional medical treatment } \\
\text { More than } 5 \text { visits to GP in the last year } \\
\text { Had visited or was visiting a hospital outpatient clinic } \\
\text { Had been admitted to hospital with asthma during } \\
\text { the last } 5 \text { years }\end{array}$ & $\begin{array}{l}56 \\
29 \\
17 \\
29 \\
38\end{array}$ & $\begin{array}{l}11 \\
44 \\
55 \\
72 \\
72\end{array}$ & $\begin{array}{ll}< & 0.05 \\
< & 0.05 \\
< & 0.01 \\
< & 0.001 \\
< & 0.001\end{array}$ \\
\hline
\end{tabular}


department during the last three months of the study. The questionnaire was sent to the 48 patients who gave consent. Thirty six $(75 \%)$ completed the questionnaire, of whom 18 had been admitted to the medical ward and 18 discharged home from the accident and emergency department (table 2).

Comparison of patients admitted to a medical ward with those discharged from the accident and emergency department showed that $(a)$ patients admitted were less likely to return to work or normal activities within $\mathbf{4 8}$ hours of discharge from hospital $(44 \% v 89 \%, \mathrm{p}<0.05)$; (b) patients admitted were more likely to require further medical treatment after discharge $(44 \% v 28 \%, p<0.05)$-this was usually given by their general practitioner; $(c)$ patients admitted were more likely to have visited their general practitioner more then five times during the previous year $(55 \% v 17 \%, \mathrm{p}<0.01)$; (d) patients admitted were more likely to have attended a hospital outpatient clinic $(72 \% v 28 \%, \mathrm{p}<0.001)$ or to have been admitted to hospital during the previous five years $(72 \% v$ $38 \%, \mathrm{p}<0.001)$.

\section{Discussion}

The aim of this study was to record the information available on all patients with asthma attending the accident and emergency department during 12 months. To avoid missing patients with atypical presentations, the accident and emergency records of all patients with chest complaints were reviewed (apart from those with chest pain, which was excluded after a pilot study). We are unlikely to have included many patients with problems other than asthma since, of the patients for whom details were recorded, only $7 \%$ had no previous history of asthma and $80 \%$ of the patients were under 40 years and the diagnosis of asthma should be reasonably straightforward in this age group. Asthma constituted $\mathbf{0 . 4 8 \%}$ of the total work load and $2.3 \%$ of the work load if trauma is excluded.

The asthmatic patients who visited the accident and emergency department may be divided into those who wanted a repeat inhaler $(16 \%)$, those who required treatment but were then discharged home $(52 \%)$, and those who required admission to a medical ward $(32 \%)$. The excess number of patients seen at the weekend was equal to the excess number discharged home, suggesting that they were patients with milder exacerbations visiting the accident and emergency department when their general practitioner was less accessible. Many patients had deteriorated because they had run out of medications. The increased attendance in the autumn has been noted in previous studies of hospital admissions, ${ }^{15-17}$ and this is the time when deaths from asthma are more likely to occur. ${ }^{18}$
One of the most striking features of this study was the variable frequency with which data were recorded. The assessment criteria we chose to look at are of necessity arbitrary, and their relative value in assessing the severity of asthma needs to be determined. The recording of observations was low, only one third of the case notes having a comment on the presence or absence of dyspnoea and $13 \%$ a comment on ability to speak. Incomplete data recording may reflect the tendency not to record negative findings. Alternatively, casualty officers may not be familiar with the clinical features associated with severe asthma. Heart rate was usually recorded, whereas an objective assessment of airflow obstruction was unusual; only one in 10 patients had their peak flow rate measured at all, and only one in 40 both before and after treatment. A similar finding was reported from South Africa, ${ }^{19}$ where neither pulsus paradoxus nor airflow obstruction had been measured in 13 patients with asthma attending an accident and emergency department, whereas in studies in the United States over $80 \%$ of patients had had both measurements. ${ }^{1314}$

The question of how the severity of asthma might best be assessed clinically has been considered in previous studies using $\mathrm{FEV}_{1}$ or arterial oxygen tension as the objective measurement of severity. ${ }^{20}$ Difficulty in speaking and pulsus paradoxus will detect patients with moderately severe asthma ${ }^{21}$ and central cyanosis patients with very severe asthma. Heart rate has been identified as one of the more important predictors of severity, irrespective of treatment, a heart rate above 110 beats/min indicating moderately severe asthma and above 130 beats/min severe asthma with an increased likelihood of complications. ${ }^{25}$ In this study heart rate did not differ between patients admitted to a medical ward and those discharged home. This contrasts with a study in general practice, where patients admitted to hospital had a higher heart rate than those treated at home, though the difference between the two groups was less for adults ( 13 beats/min) than for children ( 24 beats/min). ${ }^{22}$ Our findings suggest either that patients were being admitted or discharged inappropriately or that heart rate, per se, is a less useful measure of severity than has been suggested previously, perhaps because of the confounding effect of age. A predictive index using seven presenting factors has been proposed to help to determine the severity of asthma ${ }^{12}$ but subsequent studies have not confirmed its value in the accident and emergency department. ${ }^{1314}$ Our patients could not be classified by this index since, of the seven predictive factors, only heart rate was recorded in more then $40 \%$ of patients.

It is difficult to gauge retrospectively whether admissions and discharges were appropriate, but we 
have no specific evidence to suggest that they were not. Among the patients we wrote to at home, those discharged from the accident and emergency department returned to normal activities sooner and required less additional medication than those discharged from a medical ward, and only one patient relapsed within 10 days. Again, this contrasts with one study in the United States, where more patients were discharged at first attendance- $86 \%$ as opposed to $60 \%$ in our study - but the relapse rate was higher$20 \%$ within 10 days, most then requiring admission to hospital. ${ }^{13}$

The main disappointment in this study is the paucity of objective measurements of airflow obstruction. $\mathrm{FEV}_{1}$ was never measured and peak flow rate was measured in 17 patients only. Peak flow meters are available in the accident and emergency department and many of the casualty officers had been students in Southampton, where the importance of measuring airflow obstruction is emphasised from the second year onwards. Measurement of peak flow rate is less complicated than that of blood pressure, yet patients were five times more likely to have blood pressure measured. The high rate of recording of heart rate $(84 \%)$ and blood pressure $(63 \%)$ is probably because these measurements are made routinely by the nursing staff.

The fact that there were no obvious problems in the patients in whom peak flow was not measured is no ground for complacency. A recent study of deaths in the accident and emergency department of a large district general hospital found seven deaths from asthma over a period of five years. ${ }^{23}$ The perception of disability varies considerably between patients and asthma is easily underestimated. ${ }^{24} 25$ Deaths from asthma are rare in relation to the number of patients seen in an accident and emergency department, and the aim of an objective measurement of airflow obstruction is to try to identify the patients most at risk. An almost invariable feature of deaths from asthma has been the absence of objective measures of airflow obstruction before death, both at home and in hospital.

It is difficult to ensure that peak flow rate is measured routinely in an accident and emergency department because of the rapid turnover of staff, the wide range of problems they have to look at, and difficulty in keeping apparatus where it can always be found easily. The management of asthma in a well staffed accident and emergency department in a teaching hospital is unlikely to be of a lower standard than elsewhere. Casualty officers are seeing a lot of patients with asthma and continued efforts must be made to improve the objective assessment of the severity of this condition.

We thank Mr Martin Harman for assistance with computing and $\mathrm{Mr}$ David Machin for statistical advice.

\section{References}

1 Office of Population Censuses and Surveys. Trends in respiratory mortality 1951-1975. London: HMSO, 1981.

2 Arnold AG, Lane DJ, Zapata E. The speed of onset and severity of acute severe asthma. $\mathrm{Br} J$ Dis Chest 1982;76:157-63.

3 Bellamy D, Collins JV. "Acute" asthma in adults. Thorax 1979;34:36-9.

4 Cochrane GM, Clark TJH. A survey of asthma mortality in patients between ages 35-64 in Greater London Hospitals in 1971. Thorax 1975;30:300-5.

5 Cooke NJ, Crompton GK, Grant IWB. Observations on the management of acute bronchial asthma. $\mathrm{Br} J \mathrm{Dis}$ Chest 1979;73:157-63.

6 Rebuck AS, Reed J. Assessment and management of severe asthma. Am J Med 1971;51:788-98.

7 Subcommittee of the Research Committee, British Thoracic Association. Death from asthma in two regions of England. Br Med J 1982;285:1251-5.

8 Hetzel MR, Clark TJH, Branthwaite MA. Asthma: analysis of sudden deaths and ventilatory arrests in hospital. Br Med J 1977;i:808-11.

9 Macdonald JB, Macdonald ET, Seaton A, Williams DA. Asthma deaths in Cardiff 1963-74: 53 deaths in hospital. Br Med J 1976;ii:721-3.

10 Macdonald JB, Seaton A, Williams DA. Asthma deaths in Cardiff 1963-74: 90 deaths outside hospital. $\mathrm{Br} \mathrm{Med} \mathrm{J}$ 1976;i:1493-5.

11 Ormerod LP, Stableforth DE. Asthma mortality in Birmingham 1975-77: 53 deaths. Br Med J 1980; 280:687-90.

12 Fischl MA, Pitchenik A, Gardner LB. An index predicting relapse and need for hospitalisation in patients with acute bronchial asthma. $N$ Engl J Med 1981;305:783-9.

13 Rose CC, Murphy JG, Schwartz JS. Performance of an index predicting the response of patients with acute bronchial asthma to intensive emergency department treatment. $N$ Engl J Med 1984;310:573-7.

14 Centor RM, Yarbrough B, Wood JP, Inability to predict relapse in acute asthma. $N$ Engl J Med 1984;310:577-80.

15 Ashley JSA. Seasonal trends in childhood asthma. $\mathrm{Br}$ Med J 1983;287:1721.

16 Ayres J. Trends in acute respiratory illnesses in general practice. Thorax 1984;39:687.

17 Khot A, Burn R, Evans N, Lenney C, Lenney W. Seasonal variation and time trends in childhood asthma in England and Wales 1975-81. Br Med J 1984;289:235-7.

18 Khot A, Burn R. Seasonal variation and time trends of death from asthma in England and Wales 1960-82. Br Med J 1984;289:233-4.

19 Westerman DE, Benator SR, Potgieter PD, Ferguson AD. Identification of the high-risk asthmatic patient. Am J Med 1979;66:565-72.

20 Rees HA, Miller JS, Donald KW. A study of the clinical course and arterial blood gas tensions in patients with status asthmaticus. $Q J$ Med 1968;37:541-61.

21 Knowles GK, Clark TJH. Pulsus paradoxus as a valuable sign indicating severity of asthma. Lancet 1973;ii:1356-9.

22 Arnold AG, Lane DJ, Zapata E. Acute severe asthma: factors that influence hospital referral by the general practitioner and self-referral by the patient. $\mathrm{Br} J \mathrm{Dis}$ Chest 1983;77:51-9.

23 Shalley MJ, Cross AB. Which patients are likely to die in an accident and emergency department? Br Med J 1984;289:419-21.

24 Rubinfield AR, Pain MCF. Perception of asthma. Lancet $1976 ; \mathrm{i}: 882-7$.

25 Burdon JGW, Juniper EF, Killian KJ, Hargreave FE, Campbell EJM. The perception of breathlessness in asthma. Am Rev Respir Dis 1982;126:825-8. 